Original Article

\title{
Differential effects of saturated and unsaturated fatty acids on vascular reactivity in isolated mesenteric and femoral arteries of rats
}

\author{
Rany Vorn ${ }^{1}$ and Hae Young Yoo ${ }^{2, *}$ \\ 'Graduate School, Chung-Ang University, ${ }^{2}$ Department of Nursing, Chung-Ang University, Seoul 06974, Korea
}

\author{
ARTICLE INFO \\ Received July 10, 2019 \\ Revised August 3, 2019 \\ Accepted August 4, 2019 \\ *Correspondence \\ Hae Young Yoo \\ E-mail: hyoo@cau.ac.kr
}

Key Words

Alpha-adrenergic receptors

Fatty acids

Femoral artery

Mesenteric artery

Vasoconstriction

\begin{abstract}
Free fatty acid (FFA) intake regulates blood pressure and vascular reactivity but its direct effect on contractility of systemic arteries is not well understood. We investigated the effects of saturated fatty acid (SFA, palmitic acid), polyunsaturated fatty acid (PUFA, linoleic acid), and monounsaturated fatty acid (MUFA, oleic acid) on the contractility of isolated mesenteric (MA) and deep femoral arteries (DFA) of Sprague-Dawley rats. Isolated MA and DFA were mounted on a dual wire myograph and phenylephrine ( $\mathrm{PhE}, 1-10 \mu \mathrm{M})$ concentration-dependent contraction was obtained with or without FFAs. Incubation with $100 \mu \mathrm{M}$ of palmitic acid significantly increased PhE-induced contraction in both arteries. In MA, treatment with $100 \mu \mathrm{M}$ of linoleic acid decreased $1 \mu \mathrm{M}$ PhE-induced contraction while increasing the response to higher PhE concentrations. In DFA, linoleic acid slightly decreased PhEinduced contraction while $200 \mu \mathrm{M}$ oleic acid significantly decreased it. In MA, oleic acid reduced contraction at low $\mathrm{PhE}$ concentration $(1$ and $2 \mu \mathrm{M})$ while increasing it at $10 \mu \mathrm{M}$ PhE. Perplexingly, depolarization by $40 \mathrm{mM} \mathrm{KCl-induced} \mathrm{contraction} \mathrm{of} \mathrm{MA}$ was commonly enhanced by the three fatty acids. The $40 \mathrm{mM} \mathrm{KCl}$-contraction of DFA was also augmented by linoleic and oleic acids while not affected by palmitic acid. SFA persistently increased alpha-adrenergic contraction of systemic arteries whereas PUFA and MUFA attenuated PhE-induced contraction of skeletal arteries. PUFA and MUFA concentration-dependent dual effects on MA suggest differential mechanisms depending on the types of arteries. Further studies are needed to elucidate underlying mechanisms of the various effects of FFA on systemic arteries.
\end{abstract}

\section{INTRODUCTION}

Cardiovascular disease (CVD) remains the leading cause of death worldwide [1]. Each year 17.3 million deaths are caused by CVD, which is expected to increase to more than 23.6 million by 2030 [2]. CVD is caused by non-modifiable risk factors such as aging, sex, and family history; however, modifiable factors have a greater impact on CVD development, including hypertension, tobacco use, physical inactivity, diabetes, unhealthy diet, overweight, and obesity [3].
An unhealthy diet, including excessive intake of salt, fats, or alcohol, and lack of fruit and vegetable consumption, is associated with increased risk of developing chronic disease. An unhealthy diet has been associated with coronary heart disease [4], type 2 diabetes [5], and metabolic syndrome [6]. These risk factors have been associated with endothelial dysfunction through various complex mechanisms [7]. Impairment of endothelial function is crucial in increasing vascular tone [8]. Vascular endothelium plays a significant role in regulating vascular function via production of vasoactive factors [9].

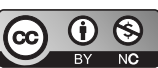

This is an Open Access article distributed under the terms of the Creative Commons Attribution Non-Commercial License, which permits unrestricted non-commercial use, distribution, and reproduction in any medium, provided the original work is properly cited. Copyright @ Korean J Physiol Pharmacol, pISSN 1226-4512, elSSN 2093-3827
Author contributions: R.V. performed the myograph experiments, and H.Y.Y. supervised and coordinated the study. R.V. and H.Y.Y. wrote the manuscript. All authors have approved the final version of the manuscript. 
According to the World Health Organization, salt intake lower than $5 \mathrm{~g}$ per day is recommended for preventing CVD [10]. In 2006, the American Heart Association also encouraged regulating fat intake to prevent CVD, recommending limiting the intake of saturated fat to $7 \%$ of total energy, trans fat to $1 \%$, and cholesterol to $300 \mathrm{mg}$ per day by choosing lean meats and vegetable alternatives, and fat-free (skim) or low-fat ( $1 \%$ fat) dairy products [11]. The most recent American Heart Association guidelines recommend a dietary pattern that achieves 5\% to $6 \%$ of calories from saturated fat [12].

The risk of CVD is increased by saturated fatty acid (SFA) intake [13], and CVD risk reduction is observed with decreased SFA intake [14]. However, monounsaturated fatty acids (MUFAs) and polyunsaturated fatty acids (PUFAs) may have a positive effect on the cardiovascular system. Most recent intervention studies suggest that replacing SFAs with PUFAs is beneficial in reducing the risk of CVD [15-17]. However, the effects of replacing SFAs with MUFAs are still unclear because of the studies' small sample size $[14,18]$.

Elevated levels of fatty acids may cause vascular dysfunction by reducing nitric oxide (NO) or enhancing the oxidative stress in endothelial cells $[19,20]$. Animal and human studies suggest that free fatty acids (FFAs) in both high and physiological concentrations cause vascular dysfunction through impaired endotheliumdependent relaxation. Effects of FFAs have been reported in various vascular beds such as mesenteric arteries [21], femoral arteries [22], aortic arteries [23], and from human leg or forearm [24-27]. FFAs may act as either proinflammatory or anti-inflammatory agents depending on their chemical structure [28]. The effect of physiological plasma concentrations of FFAs on systemic arteries, especially the smooth muscle contractility, has not been fully understood. Among all body organs, the digestive system and skeletal muscles occupy the largest volume. Therefore, the tone and reactivity of mesenteric and skeletal arteries may represent the overall response of systemic circulation to FFAs. Therefore, the purpose of this study was to investigate the effects of representative SFA (palmitic acid), PUFA (linoleic acid), and MUFA (oleic acid) on the contractility of isolated mesenteric (MA) and deep femoral arteries (DFA) of rats.

\section{METHODS}

\section{Animals and arterial ring preparation}

This animal study was approved by the Institutional Animal Care and Use Committee (IACUC) in Chung-Ang University (IACUC approval No. 2015-00012). Adult male Sprague-Dawley rats (7-8 weeks old) were used in this experiment. Pentobarbital sodium $(60-100 \mathrm{mg} / \mathrm{kg})$ was injected intraperitoneally to anesthetize the rats before the operation. Full anesthesia was confirmed by limb withdrawal after toe pinching. The intestine and proximal hind legs were quickly removed and placed in a normal tyrode (NT) solution at $4^{\circ} \mathrm{C}$. The second and third branches of the mesenteric arteries (MAs) and deep femoral arteries (DFAs) were isolated rapidly and cut into $2.5-3 \mathrm{~mm}$ long segments (inner diameter: $200-300 \mu \mathrm{m}$ ).

\section{Isometric tension protocol}

The arterial rings were mounted on two $25 \mu \mathrm{m}$ tungsten wires of a multiwire myograph system (620 M; DMT, Aarhus, Denmark). Each myograph chamber was filled with $5 \mathrm{ml}$ of physiological salt solution (PSS). A segment of the arterial ring was stabilized in PSS with continuous gas bubbling $\left(21 \% \mathrm{O}_{2}, 5 \% \mathrm{CO}_{2}\right.$, and $\mathrm{N}_{2}$ balanced at $37^{\circ} \mathrm{C}$ ) to maintain $\mathrm{pH}$ at 7.4. The isometric tension was recorded by a data acquisition system (Lab Chart Pro version 8.0; ADInstruments, Sydney, Australia). The arterial rings were tested for the validity of segment preparation by determining their response to a high concentration of potassium chloride (80 mM KCl-PSS). A high concentration of $80 \mathrm{mM} \mathrm{KCl}$ was prepared by replacing $\mathrm{NaCl}$ with equimolar $\mathrm{KCl}$. The rings were washed with the PSS solution, and we waited until their resting tone returned. Endothelium-dependent relaxation was observed by full relaxation to $10 \mu \mathrm{M}$ of acetylcholine (ACh) in the presence of pre-constriction to $10 \mu \mathrm{M}$ of $\alpha$-adrenergic agonist (phenylephrine, $\mathrm{PhE}$ ). The dose-response curve of $\mathrm{PhE}$ was obtained after 30 min of incubation in PSS with or without palmitic acid $(100 \mu \mathrm{M})$, linoleic acid $(100 \mu \mathrm{M})$, and oleic acid $(200 \mu \mathrm{M})$ with different concentration increments at 5 -min intervals $(0.05 \mu \mathrm{M}, 0.1 \mu \mathrm{M}, 1$ $\mu \mathrm{M}, 2 \mu \mathrm{M}, 5 \mu \mathrm{M}$, and $10 \mu \mathrm{M})$.

Nonreceptor-mediated contraction to high concentration of potassium chloride $(40 \mathrm{mM} \mathrm{KCl})$ was investigated after the arterial segments were incubated in PSS with or without palmitic acid $(100 \mu \mathrm{M})$, linoleic acid $(100 \mu \mathrm{M})$, and oleic acid $(200 \mu \mathrm{M})$ for 30 min. Arterial segments were exposed to $40 \mathrm{mM} \mathrm{KCl}$ for $2 \mathrm{~min}$ and then washed out with PSS.

\section{Solutions and chemicals}

The composition of the NT solution was as follows (in mmol/ L): $\mathrm{NaCl} 140, \mathrm{KCl}$ 5.4, $\mathrm{NaH}_{2} \mathrm{PO}_{4}$ 0.33, 4-(2-hydroxyethyl)-1-piperazineethanesulfonic acid 10, glucose $10, \mathrm{MgCl}_{2} 1$, and $\mathrm{CaCl}_{2}$ 1.8 (adjusted with $\mathrm{NaOH}$ to $\mathrm{pH}$ 7.4). The composition of the PSS solution was as follows (in mmol/L): $\mathrm{NaCl} 118, \mathrm{KCl} 4, \mathrm{MgSO}_{4} 1$, $\mathrm{NaH}_{2} \mathrm{PO}_{4}$ 0.44, $\mathrm{NaHCO}_{3} 24$, glucose 5.6, and $\mathrm{CaCl}_{2}$ 1.8. The 40 $\mathrm{mM} \mathrm{KCl}-\mathrm{PSS}$ contained the following (in $\mathrm{mmol} / \mathrm{L}$ ): $\mathrm{NaCl} 82, \mathrm{KCl}$ 40, $\mathrm{MgSO}_{4} 1, \mathrm{NaH}_{2} \mathrm{PO}_{4} 0.44, \mathrm{NaHCO}_{3} 24$, glucose 5.6, and $\mathrm{CaCl}_{2}$ 1.8. A high concentration of $40 \mathrm{mM} \mathrm{KCl}$ was prepared by replacing $\mathrm{NaCl}$ with equimolar $\mathrm{KCl}$. All the solutions and chemicals were purchased from Sigma (St. Louis, MO, USA). 


\section{Statistical analysis}

Statistical analysis was conducted using OriginPro version 8.0 for Windows (Origin Lab, Northampton, MA, USA). The response to $\mathrm{PhE}$ and $40 \mathrm{mM} \mathrm{KCl}$ is expressed as percent of the 80 $\mathrm{mM}$ KCl-PSS induced maximum constriction. Data are presented as mean \pm standard error of the mean. Statistical comparisons were performed using unpaired Student's t-test, and $\mathrm{p}<0.05$ was considered statistically significant.

\section{RESULTS}

In each vessel, standard contraction by $80 \mathrm{mM} \mathrm{KCl-induced}$ depolarization was initially confirmed. Data were excluded if the contraction to $80 \mathrm{mM} \mathrm{KCl}$-induced maximum constriction was less than $1 \mathrm{~g}$. Then, $10 \mu \mathrm{M}$ PhE-induced maximum contraction was also confirmed, followed by endothelium-dependent relaxation by applying $10 \mu \mathrm{M} \mathrm{ACh}$. We used the endotheliumintact arterial rings, i.e. $>60 \%$ relaxation by $10 \mu \mathrm{M}$ ACh. After confirming the stable basal tone by washout of $\mathrm{PhE}$ and $\mathrm{ACh}$, the concentration-dependent PhE-induced contractions of MA and DFA were obtained by cumulative increase of $\mathrm{PhE}$ from 0.05 to 10 $\mu \mathrm{M}$ (Fig. 1A, D).

Pretreatment with $100 \mu \mathrm{M}$ palmitic acid alone did not produce any effect on the basal tone of MA and DFA but significantly augmented PhE-induced contractions in both arteries (Fig. 1B, C, E, F). In DFA, it was notable that palmitic acid incubation revealed the PhE-contraction even at $0.1 \mu \mathrm{M}$ (Fig. 1E, F).

Pretreatment with $100 \mu \mathrm{M}$ linoleic acid alone did not change the basal tone of MA and DFA (Fig. 2). However, it blunted the 1 $\mu \mathrm{M}$ PhE-induced contraction of MA while increasing it at $2 \mu \mathrm{M}$ $\mathrm{PhE}$ and above (Fig. 2A-C). In contrast, pretreatment of DFA with linoleic acid tended to decrease PhE-induced contractions. However, this effect was not statistically significant (Fig. 2D-F).

Pretreatment with $200 \mu \mathrm{M}$ oleic acid alone did not change the basal tone of MA and DFA (Fig. 3), but reduced PhE-induced contraction of $\mathrm{MA}$ at 1 and $2 \mu \mathrm{M} \mathrm{PhE}$ while augmenting it at 10 $\mu \mathrm{M}$ (Fig. 3A-C). In contrast, pretreatment of DFA with oleic acid significantly suppressed PhE-induced contractions $(1 \mu \mathrm{M}$ to 10 $\mu \mathrm{M}$ ) (Fig. 3D-F).

To get a mechanistic clue for the changes of vascular contractions by FFAs, we examined the effects of FFAs on membrane depolarization-induced contractions of MA and DFA. Increasing the extracellular $\mathrm{K}^{+}$concentration from 4 to $40 \mathrm{mM}$ would induce moderate depolarization to around $-15 \mathrm{mV}$, which activates L-
MA

A

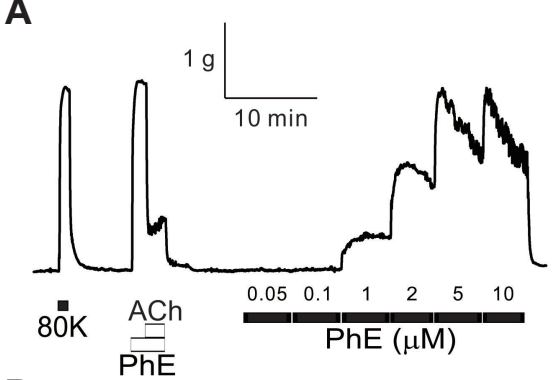

B

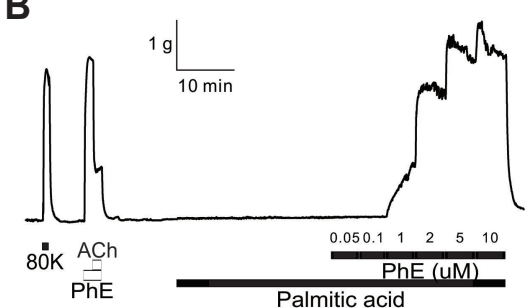

C

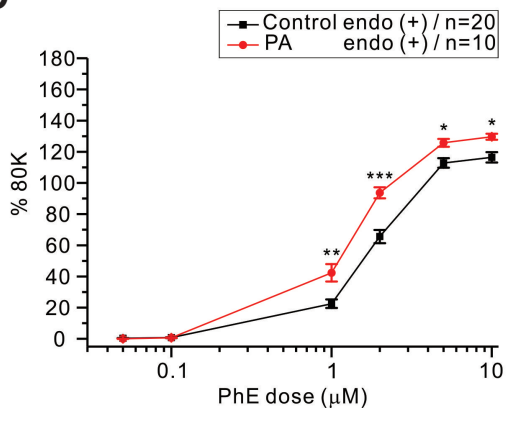

D

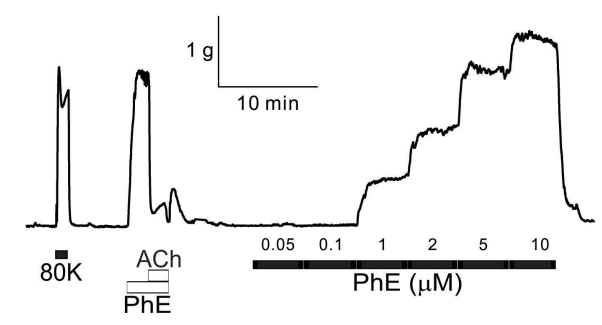

E

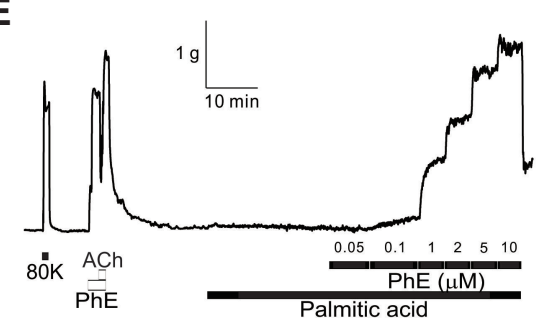

F

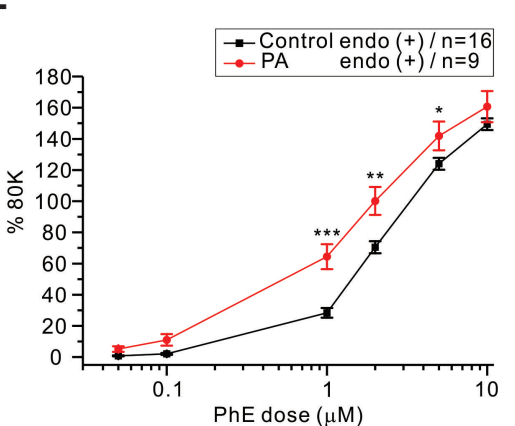

Fig. 1. Effect of saturated fatty acid on phenylephrine (PhE)-induced contractile response in mesenteric arteries (MAs) and deep femoral arteries (DFAs) of rat. Original trace of the dose-dependent response curve of PhE in control isolated MAs and DFAs. Representative trace of PhE-induced contraction in MAs $(A, B)$ and DFAs $(D, E)$ with and without palmitic acid. After $30 \mathrm{~min}$ of exposure to physiological salt solution with or without palmitic acid, doseresponse curves of different $\mathrm{PhE}$ concentrations $(0.05 \mu \mathrm{M}, 0.1 \mu \mathrm{M}, 1 \mu \mathrm{M}, 2 \mu \mathrm{M}, 5$ $\mu \mathrm{M}$, and $10 \mu \mathrm{M})$ are shown. Summaries of $\mathrm{PhE}$ dose-response curve in MAs (C) and DFAs (F) are presented as means \pm standard error of the mean. Endo, endothelial cells; ACh, acetylcholine. ${ }^{*} p<0.05$, ${ }^{* *} \mathrm{p}<0.01,{ }^{* * *} \mathrm{p}<0.001$. 
MA

A

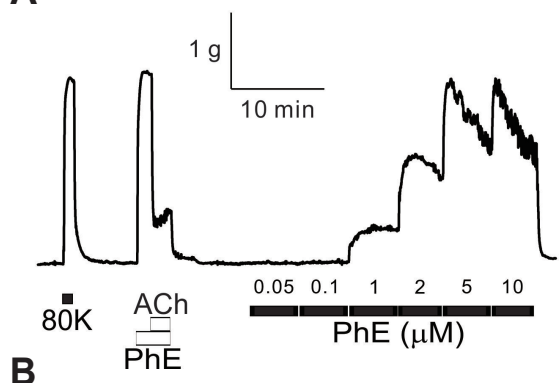

B

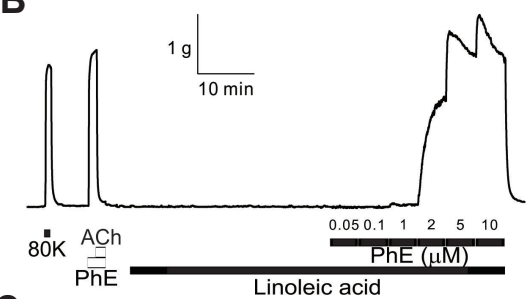

C

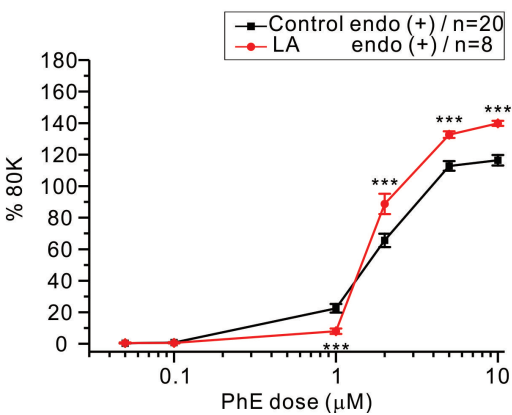

DFA

D

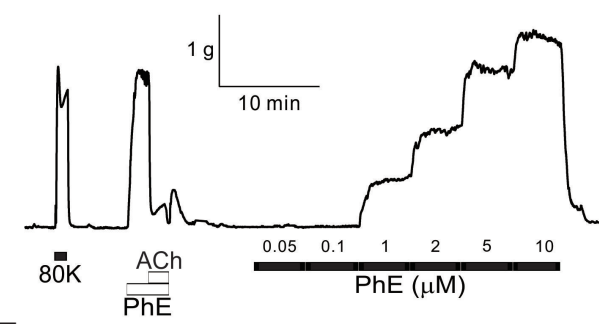

E

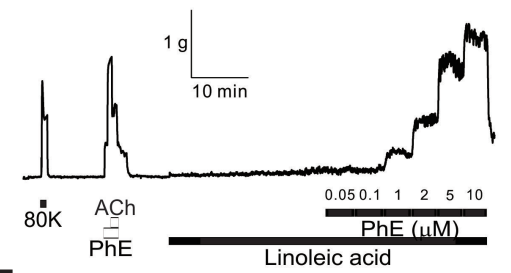

$\mathbf{F}$

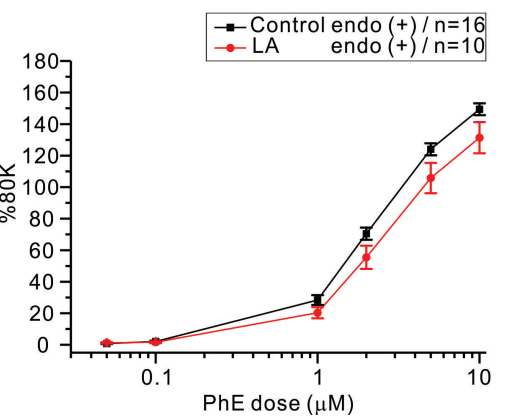

Fig. 2. Effect of polyunsaturated fatty acid on phenylephrine (PhE)-induced contractile response in mesenteric arteries (MAs) and deep femoral arteries (DFAs) of rat. Original trace of the dose-dependent response curve of $\mathrm{PhE}$ in control isolated MAs and DFAs. Representative trace of PhE-induced contraction in MAs $(A, B)$ and DFAs (D, E) with and without linoleic acid. After $30 \mathrm{~min}$ of exposure to physiological salt solution with or without palmitic acid, dose-response curves of different PhE concentrations $(0.05 \mu \mathrm{M}, 0.1 \mu \mathrm{M}, 1$ $\mu \mathrm{M}, 2 \mu \mathrm{M}, 5 \mu \mathrm{M}$, and $10 \mu \mathrm{M})$ are shown. Summaries of PhE dose-response curve in MAs (C) and DFA (F) are presented as mean \pm standard error of the mean. Endo, endothelial cells; ACh, acetylcholine. ${ }^{* * *} p<0.001$. type voltage dependent $\mathrm{Ca}^{2+}$ channels (VDCC) in smooth muscle. The $40 \mathrm{mM} \mathrm{KCl}$-induced contraction (40K-contraction) was 55.06 $\pm 2.53 \%$ and $76.68 \pm 5.03 \%$ of $80 \mathrm{mM} \mathrm{KCl}$-induced contraction in MA and DFA, respectively (Fig. 4). In MA, the 40K-contraction was increased by pretreatment with palmitic acid (67.16 $\pm 2.17 \%)$, linoleic acid (71.31 $\pm 2.38 \%$ ), and oleic acid (87.76 $\pm 1.94 \%)$ (Fig. $4 \mathrm{~A})$. In DFA, the $40 \mathrm{~K}$-contraction was increased by pretreatment with oleic acid $(95.03 \pm 3.48 \%)$ and linoleic acid $(101.68 \pm 4.20 \%)$. However, palmitic acid pretreatment did not affect DFA $40 \mathrm{~K}-$ contraction (Fig. 4B).

\section{DISCUSSION}

The present study showed that the dose-dependent PhEinduced contraction was enhanced in the presence of palmitic acid with a physiological concentration in MAs and DFAs. Furthermore, the application of oleic acid attenuated $\mathrm{PhE}$-induced contraction in both types of arteries. Additionally, incubation with linoleic acid in the artery induced different responses to PhE-induced contraction in MAs and DFAs. The FFAs used in our study are the primary fatty acids circulating in blood plasma concentration $[21,29]$. The FFAs may have different effects de- pending on the vessel types perfusing different organs and tissues $[19,21,30]$. The present study aimed to extend our previous findings investigating the effects of actual nutrient rich (termed nutrition full, NF) solution in vessels [31]. These results may elucidate the specific fatty acids responsible for the previous inconsistent results observed using NF solution in mesenteric and femoral arteries [31].

SFAs, such as palmitic acid, are positively associated with an increased risk of CVD $[13,32]$. However, the underlying mechanism of how SFAs can increase vascular tone and CVD is unknown [33]. In vitro, palmitic acid exposure attenuated the response to endothelium-dependent relaxation in both physiological and high concentrations $[21,22,34]$, which suggested that FFAs may impair the production of endothelium-derived NO. Elevated FFAs induced NO production in endothelial cells from rat aorta [35], and it is well known that NO released from the endothelium has a significant function in regulating vascular tone as a vasodilator $[9,36]$. NO and superoxide $\left(\mathrm{O}_{2}^{-}\right)$play a crucial role in the production of peroxynitrite $\left(\mathrm{ONOO}^{-}\right)$[37].

The incubation of linoleic acid, one of PUFA, showed different responses between MAs and DFAs in the present study. A previous study showed that the application of linoleic acid induces uncoupled endothelial NO synthase (eNOS) leading to increased $\mathrm{O}_{2}^{-}$ 
MA

A

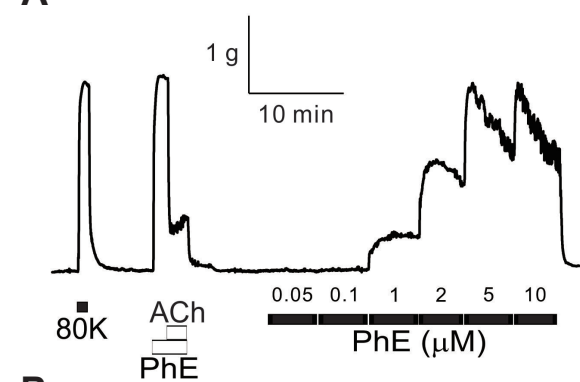

B

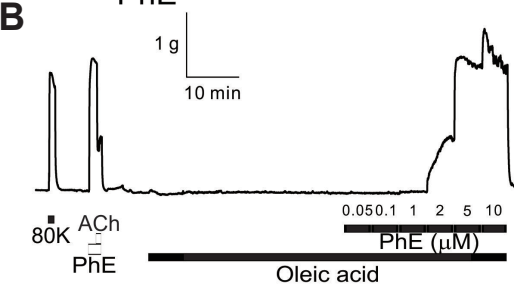

C

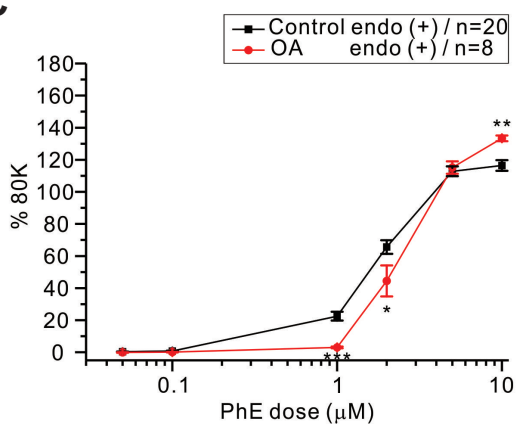

D

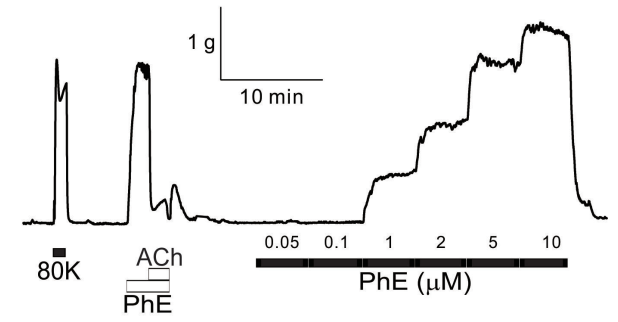

E

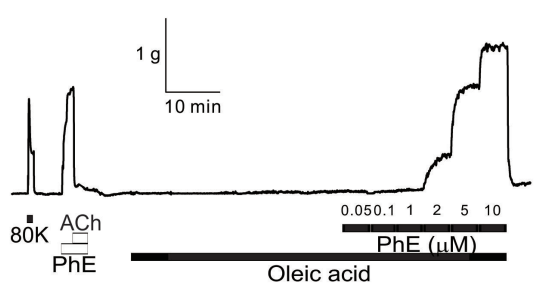

$\mathbf{F}$

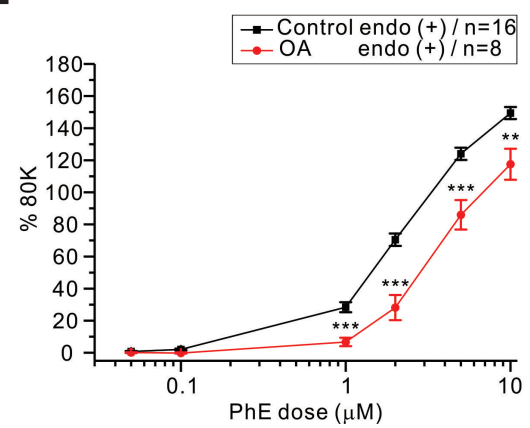

Fig. 3. Effect of monounsaturated fatty acid on phenylephrine (PhE)induced contractile response in mesenteric arteries (MAs) and deep femoral arteries (DFAs) of rat. Original trace of the dose-dependent response curve of PhE in control isolated MAs and DFAs. Representative trace of PhE-induced contraction in MAs (A, B) and DFAs (D, E) with and without oleic acid. After 30 min of exposure to physiological salt solution with or without palmitic acid, dose-response curves of different PhE concentrations $(0.05 \mu \mathrm{M}, 0.1 \mu \mathrm{M}, 1 \mu \mathrm{M}, 2$ $\mu \mathrm{M}, 5 \mu \mathrm{M}$, and $10 \mu \mathrm{M})$ are shown. Summaries of PhE dose-response curve in MAs (C) and DFA (F) of PhE are presented as mean \pm standard error of the mean. Endo, endothelial cells; ACh, acetylcholine. ${ }^{*} p<0.05,{ }^{* *} p<0.01,{ }^{* * *} p<0.001$.
MA

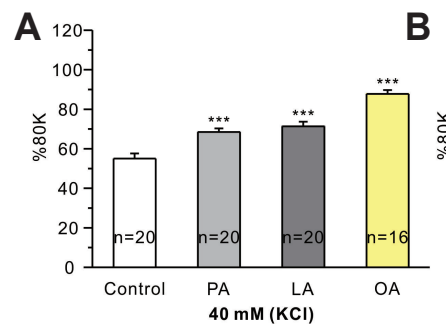

B

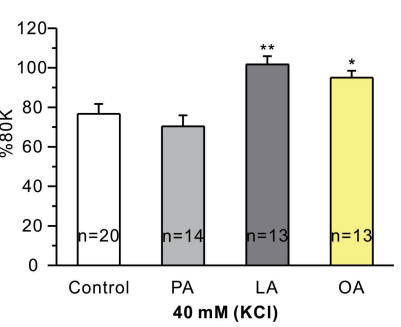

Fig. 4. Effect of fatty acids on the contractile response induced by high $\mathrm{K}^{+}$in mesenteric arteries (MAs) and deep femoral arteries (DFAs) of rat. The contractile response to $40 \mathrm{mM}$ of $\mathrm{KCl}$ in the presence or absence of palmitic acid (PA), linoleic acid (LA), oleic acid (OA) in MAs (A) and DFAs (B). ${ }^{*} \mathrm{p}<0.05,{ }^{* *} \mathrm{p}<0.01,{ }^{* * *} \mathrm{p}<0.001$.

production, which may react with $\mathrm{NO}$ to form the highly reactive intermediate $\mathrm{ONOO}^{-}$responsible for vascular dysfunction [19]. On the other hand, other studies demonstrated that linoleic acid inhibits PhE-induced contraction in rat aorta [38] and induces vascular relaxation and hyperpolarization via activation of the $\mathrm{Na}^{+} / \mathrm{K}^{+}$-ATPase pump in the coronary artery [39]. These various effects of linoleic acid on vascular contractility may explain the different arterial responses observed in the present study.
MUFAs, such as oleic acid in physiological concentration decreased PhE-induced contraction in the present study. Therefore, the application of oleic acid may prevent or improve vascular function by maintaining or increasing NO production by the endothelium [40]. A previous study demonstrated that a high-fat diet rich in unsaturated fatty acids does not decrease PhE sensitivity of the thoracic aorta in rats [41]. Additionally, oleic acid does not induce insulin resistance in cultured cardiovascular cells and it even protects against insulin resistance caused by palmitic acid or inflammatory factors, such as tumor necrosis factor $\alpha[42,43]$. However, there is evidence that oleic acid attenuates endotheliumdependent relaxation in MAs [21]. Further, the direct exposure to oleic acid enhances vascular smooth muscle cell proliferation and migration from the rat aorta $[30,44]$. These conflicting results might be due to differences in experimental conditions, animal strains, and vessels.

The present study also showed effects of FFAs on high potassium induced contraction. High potassium levels induce membrane depolarization, which activates VDCC [45]. The increase in intracellular calcium levels might be responsible for the increase of high $\mathrm{K}^{+}$-induced contraction in the presence of palmitic acid, linoleic acid, and oleic acid in our study. A previous study found that linoleic acid increases the activation of intracellular calcium 
levels in endothelial cells from the pulmonary artery [19]. Even though the incubation with oleic acid decreased sensitivity of alpha adrenergic constriction, high $\mathrm{K}^{+}$-induced contraction was increased in the presence of oleic acid. The increase in high $\mathrm{K}^{+}$induced contraction with unsaturated fatty acids may be due to VDCC, which induces the contraction by regulating intracellular calcium release [19]. However, the vascular constriction in response to alpha adrenergic agonists is regulated by a more complex mechanism including receptor operated calcium influx via Rho-kinase or protein kinase C (PKC) activation [46]. Alpha adrenergic agonists such as $\mathrm{PhE}$ can activate phospholipase $\mathrm{C}$ which leads to the formation of inositol triphosphate and diacylglycerol [47], which induces phosphorylation of PKC and intracellular calcium release [46]. A previous study showed that the infusion of FFAs increases PKC activity in rat aortic endothelium [35]. Thus, increased PKC activity might contribute to the enhancement of PhE-induced contraction in the present study. Further investigation is required to clarify the obtained results.

In the present study, we found that SFAs in physiological concentration augments sensitivity to PhE-induced contraction in rat MAs and DFAs, whereas MUFAs improve vascular relaxation. On the basis of our finding, we suggest that the consumption of foods containing SFAs may increase the risk of CVD. Furthermore, a diet that replaces saturated fat with unsaturated fat within normal range may prevent the increase of vascular tension.

In summary, we conclude that both saturated and unsaturated fatty acids have diverse effects on vascular function depending on vascular beds. Our findings may serve as basic evidence for exploring the underlying mechanism of the effect of FFAs on vascular contractility.

\section{ACKNOWLEDGEMENTS}

This study was supported by the National Research Foundation of Korea (NRF) grant funded by Korea government (MSIT) (grant no. NRF-2019R1F1A1062965).

\section{CONFLICTS OF INTEREST}

The authors declare no conflicts of interest.

\section{REFERENCES}

1. Pagidipati NJ, Gaziano TA. Estimating deaths from cardiovascular disease: a review of global methodologies of mortality measurement. Circulation. 2013;127:749-756.

2. Mozaffarian D, Benjamin EJ, Go AS, Arnett DK, Blaha MJ, Cushman M, Das SR, de Ferranti S, Després JP, Fullerton HJ, Howard VJ, Huffman MD, Isasi CR, Jiménez MC, Judd SE, Kissela BM,
Lichtman JH, Lisabeth LD, Liu S, Mackey RH, et al. Heart disease and stroke statistics-2016 update: a report from the American Heart Association. Circulation. 2016;133:e38-e360.

3. Gaziano TA. Reducing the growing burden of cardiovascular disease in the developing world. Health Aff (Millwood). 2007;26:13-24.

4. McNaughton SA, Mishra GD, Brunner EJ. Food patterns associated with blood lipids are predictive of coronary heart disease: the Whitehall II study. Br J Nutr. 2009;102:619-624.

5. McNaughton SA, Mishra GD, Brunner EJ. Dietary patterns, insulin resistance, and incidence of type 2 diabetes in the Whitehall II Study. Diabetes Care. 2008;31:1343-1348.

6. Deshmukh-Taskar PR, O'Neil CE, Nicklas TA, Yang SJ, Liu Y, Gustat J, Berenson GS. Dietary patterns associated with metabolic syndrome, sociodemographic and lifestyle factors in young adults: the Bogalusa Heart Study. Public Health Nutr. 2009;12:2493-2503.

7. Münzel T, Gori T, Bruno RM, Taddei S. Is oxidative stress a therapeutic target in cardiovascular disease? Eur Heart J. 2010;31:27412748 .

8. Bonetti PO, Lerman LO, Lerman A. Endothelial dysfunction: a marker of atherosclerotic risk. Arterioscler Thromb Vasc Biol. 2003; 23:168-175.

9. Sandoo A, van Zanten JJ, Metsios GS, Carroll D, Kitas GD. The endothelium and its role in regulating vascular tone. Open Cardiovasc Med J. 2010;4:302-312.

10. Hooper L, Bartlett C, Davey SG, Ebrahim S. Advice to reduce dietary salt for prevention of cardiovascular disease. Cochrane Database Syst Rev. 2004;(1):CD003656.

11. American Heart Association Nutrition Committee, Lichtenstein AH, Appel LJ, Brands M, Carnethon M, Daniels S, Franch HA, Franklin B, Kris-Etherton P, Harris WS, Howard B, Karanja N, Lefevre M, Rudel L, Sacks F, Van Horn L, Winston M, Wylie-Rosett J. Diet and lifestyle recommendations revision 2006: a scientific statement from the American Heart Association Nutrition Committee. Circulation. 2006;114:82-96.

12. Eckel RH, Jakicic JM, Ard JD, de Jesus JM, Houston Miller N, Hubbard VS, Lee IM, Lichtenstein AH, Loria CM, Millen BE, Nonas CA, Sacks FM, Smith SC Jr, Svetkey LP, Wadden TA, Yanovski SZ, Kendall KA, Morgan LC, Trisolini MG, Velasco G, et al. 2013 AHA/ ACC guideline on lifestyle management to reduce cardiovascular risk: a report of the American College of Cardiology/American Heart Association Task Force on Practice Guidelines. Circulation. 2014;129(25 Suppl 2):S76-S99.

13. DiNicolantonio JJ, Lucan SC, O'Keefe JH. The evidence for saturated fat and for sugar related to coronary heart disease. Prog Cardiovasc Dis. 2016;58:464-472.

14. Hooper L, Martin N, Abdelhamid A, Davey Smith G. Reduction in saturated fat intake for cardiovascular disease. Cochrane Database Syst Rev. 2015;(6):CD011737.

15. Kris-Etherton PM, Fleming JA. Emerging nutrition science on fatty acids and cardiovascular disease: nutritionists' perspectives. Adv Nutr. 2015;6:326S-337S.

16. Vafeiadou K, Weech M, Altowaijri H, Todd S, Yaqoob P, Jackson KG, Lovegrove JA. Replacement of saturated with unsaturated fats had no impact on vascular function but beneficial effects on lipid biomarkers, E-selectin, and blood pressure: results from the randomized, controlled Dietary Intervention and VAScular function (DIVAS) study. Am J Clin Nutr. 2015;102:40-48. 
17. Siri-Tarino PW, Sun Q, Hu FB, Krauss RM. Saturated fatty acids and risk of coronary heart disease: modulation by replacement nutrients. Curr Atheroscler Rep. 2010;12:384-390.

18. Jakobsen MU, O'Reilly EJ, Heitmann BL, Pereira MA, Bälter K, Fraser GE, Goldbourt U, Hallmans G, Knekt P, Liu S, Pietinen P, Spiegelman D, Stevens J, Virtamo J, Willett WC, Ascherio A. Major types of dietary fat and risk of coronary heart disease: a pooled analysis of 11 cohort studies. Am J Clin Nutr. 2009;89:1425-1432.

19. Saraswathi V, Wu G, Toborek M, Hennig B. Linoleic acid-induced endothelial activation: role of calcium and peroxynitrite signaling. $J$ Lipid Res. 2004;45:794-804.

20. Chinen I, Shimabukuro M, Yamakawa K, Higa N, Matsuzaki T, Noguchi K, Ueda S, Sakanashi M, Takasu N. Vascular lipotoxicity: endothelial dysfunction via fatty-acid-induced reactive oxygen species overproduction in obese Zucker diabetic fatty rats. Endocrinology. 2007;148:160-165.

21. Sainsbury CA, Sattar N, Connell JM, Hillier C, Petrie JR. Nonesterified fatty acids impair endothelium-dependent vasodilation in rat mesenteric resistance vessels. Clin Sci (Lond). 2004;107:625-629.

22. Lundman P, Tornvall P, Nilsson L, Pernow J. A triglyceride-rich fat emulsion and free fatty acids but not very low density lipoproteins impair endothelium-dependent vasorelaxation. Atherosclerosis. 2001;159:35-41.

23. Sun X, Hou N, Han F, Guo Y, Hui Z, Du G, Zhang Y. Effect of high free fatty acids on the anti-contractile response of perivascular adipose tissue in rat aorta. J Mol Cell Cardiol. 2013;63:169-174.

24. Steinberg HO, Tarshoby M, Monestel R, Hook G, Cronin J, Johnson A, Bayazeed B, Baron AD. Elevated circulating free fatty acid levels impair endothelium-dependent vasodilation. J Clin Invest. 1997;100:1230-1239.

25. Pleiner J, Schaller G, Mittermayer F, Bayerle-Eder M, Roden M, Wolzt M. FFA-induced endothelial dysfunction can be corrected by vitamin C. JClin Endocrinol Metab. 2002;87:2913-2917.

26. Nitenberg A, Cosson E, Pham I. Postprandial endothelial dysfunction: role of glucose, lipids and insulin. Diabetes Metab. 2006;32: 2S28-2S33.

27. Watanabe S, Tagawa T, Yamakawa K, Shimabukuro M, Ueda S. Inhibition of the renin-angiotensin system prevents free fatty acidinduced acute endothelial dysfunction in humans. Arterioscler Thromb Vasc Biol. 2005;25:2376-2380.

28. Volpe CM, Nogueira-Machado JA. The dual role of free fatty acid signaling in inflammation and therapeutics. Recent Pat Endocr Metab Immune Drug Discov. 2013;7:189-197.

29. Bhagavan NV, Ha JS, Park JH, Honda SA, Rios CN, Sugiyama C, Fujitani GK, Takeuchi IK, Ha CE. Utility of serum Fatty Acid concentrations as a marker for acute myocardial infarction and their potential role in the formation of ischemia-modified albumin: a pilot study. Clin Chem. 2009;55:1588-1590.

30. Doronzo G, Viretto M, Barale C, Russo I, Mattiello L, Anfossi G, Trovati M. Oleic acid increases synthesis and secretion of VEGF in rat vascular smooth muscle cells: role of oxidative stress and impairment in obesity. Int J Mol Sci. 2013;14:18861-18880.

31. Vorn R, Yoo HY. Effects of high glucose with or without other metabolic substrates on alpha-adrenergic contractions in rat mesenteric and femoral arteries. Korean J Physiol Pharmacol. 2017;21:91-97.
32. Harvey KA, Walker CL, Pavlina TM, Xu Z, Zaloga GP, Siddiqui RA. Long-chain saturated fatty acids induce pro-inflammatory responses and impact endothelial cell growth. Clin Nutr. 2010;29:492-500.

33. Djoussé L, Benkeser D, Arnold A, Kizer JR, Zieman SJ, Lemaitre RN, Tracy RP, Gottdiener JS, Mozaffarian D, Siscovick DS, Mukamal KJ, Ix JH. Plasma free fatty acids and risk of heart failure: the Cardiovascular Health Study. Circ Heart Fail. 2013;6:964-969.

34. Gao Z, Zhang H, Liu J, Lau CW, Liu P, Chen ZY, Lee HK, Tipoe GL, Ho HM, Yao X, Huang Y. Cyclooxygenase-2-dependent oxidative stress mediates palmitate-induced impairment of endotheliumdependent relaxations in mouse arteries. Biochem Pharmacol. 2014; 91:474-482.

35. Li H, Li H, Bao Y, Zhang X, Yu Y. Free fatty acids induce endothelial dysfunction and activate protein kinase $\mathrm{C}$ and nuclear factor- $\mathrm{\kappa} \mathrm{B}$ pathway in rat aorta. Int J Cardiol. 2011;152:218-224.

36. Tousoulis D, Kampoli AM, Tentolouris C, Papageorgiou N, Stefanadis $\mathrm{C}$. The role of nitric oxide on endothelial function. Curr Vasc Pharmacol. 2012;10:4-18.

37. Ferdinandy P, Schulz R. Nitric oxide, superoxide, and peroxynitrite in myocardial ischaemia-reperfusion injury and preconditioning. Br J Pharmacol. 2003;138:532-543.

38. Engler MB. Effects of omega-3, omega- 6 and omega-9 fatty acids on vascular smooth muscle tone. Eur J Pharmacol. 1992;215:325-328.

39. Pomposiello SI, Alva M, Wilde DW, Carretero OA. Linoleic acid induces relaxation and hyperpolarization of the pig coronary artery. Hypertension. 1998;31:615-620.

40. Christon RA. Mechanisms of action of dietary fatty acids in regulating the activation of vascular endothelial cells during atherogenesis. Nutr Rev. 2003;61:272-279.

41. Medei E, Lima-Leopoldo AP, Pereira-Junior PP, Leopoldo AS, Campos DH, Raimundo JM, Sudo RT, Zapata-Sudo G, BruderNascimento T, Cordellini S, Nascimento JH, Cicogna AC. Could a high-fat diet rich in unsaturated fatty acids impair the cardiovascular system? Can J Cardiol. 2010;26:542-548.

42. Perdomo L, Beneit N, Otero YF, Escribano Ó, Díaz-Castroverde S, Gómez-Hernández A, Benito M. Protective role of oleic acid against cardiovascular insulin resistance and in the early and late cellular atherosclerotic process. Cardiovasc Diabetol. 2015;14:75.

43. Gao D, Griffiths HR, Bailey CJ. Oleate protects against palmitateinduced insulin resistance in L6 myotubes. Br J Nutr. 2009;102:15571563.

44. Greene EL, Lu G, Zhang D, Egan BM. Signaling events mediating the additive effects of oleic acid and angiotensin II on vascular smooth muscle cell migration. Hypertension. 2001;37:308-312.

45. Marchand A, Abi-Gerges A, Saliba Y, Merlet E, Lompré AM. Calcium signaling in vascular smooth muscle cells: from physiology to pathology. Adv Exp Med Biol. 2012;740:795-810.

46. Liu Z, Khalil RA. Evolving mechanisms of vascular smooth muscle contraction highlight key targets in vascular disease. Biochem Pharmacol. 2018;153:91-122.

47. Yamamura A, Guo Q, Yamamura H, Zimnicka AM, Pohl NM, Smith KA, Fernandez RA, Zeifman A, Makino A, Dong H, Yuan JX. Enhanced $\mathrm{Ca}^{2+}$-sensing receptor function in idiopathic pulmonary arterial hypertension. Circ Res. 2012;111:469-481. 